\title{
Probable Correlation between Temporomandibular Dysfunction and Vertigo in the Elderly
}

\author{
Luciana Lozza de Moraes Marchiori ${ }^{1}$ Paula Vanessa Pedron Oltramari-Navarro ${ }^{1}$ \\ Caroline Luiz Meneses-Barrivieira ${ }^{1}$ Juliana Jandre Melo ${ }^{1}$ Julya Macedo ${ }^{2}$ \\ Juliana Ribeiro Zuculin Bruniera ${ }^{1}$ Vanessa Cristina Gorres ${ }^{1}$ Ricardo de Lima Navarro ${ }^{1}$
}

\footnotetext{
1 Universidade Norte do Paraná-Unopar, Londrina, PR, Brazil

2 Faculdade Global de Umuarama-Paraná, Umuarama, PR, Brazil

Int Arch Otorhinolaryngol 2014;18:49-53.
}

\begin{abstract}
Address for correspondence Luciana Lozza de Moraes Marchiori, PhD, Campus Universitário de Londrina, Clinica de Fonoaudiologia Av. Paris, 675-Jd. Piza CEP 86041-140-Cx. P. 401, Londrina, PR, Brazil (e-mail: luciana.marchiori@unopar.br).
\end{abstract}

\begin{abstract}
Keywords

- dizziness

- aged

- temporomandibular joint dysfunction syndrome

Introduction Temporomandibular disorder (TMD) covers a variety of clinical problems, and some epidemiologic studies have tried to indicate mechanisms of interaction and association between vertigo and TMD, but this topic still is controversial.

Objective To assess the presence of vertigo in elderly patients associated with TMD. Methods A cross-sectional study was conducted with the inclusion of elderly individuals who lived independently. TMD was assessed by dental evaluation and vertigo was verified by medical history. Statistical analysis was performed using the chi-square and relative risk.

Results There was a significant association ( $p=0.0256)$ between the TMD and vertigo (odds ratio $=2.3793$ ).

Conclusion These results highlighted the importance of identifying risk factors for vertigo that can be modified through specific interventions, which is essential to prevent future episodes, as well as managing the process of rehabilitation of elderly patients in general.
\end{abstract}

\section{Introduction}

Temporomandibular joint (TMJ) disorder covers a variety of clinical problems involving the masticatory muscles, the joint itself, and associated structures to the ear region. Temporomandibular disorder (TMD) is a general term for the clinical problems that involve the masticatory muscles, the TMJ, and associated structures. ${ }^{1-3}$

Vertigo is dizziness and may be associated with several comorbidities $^{4}$ such as TMD. Some epidemiologic studies have tried to indicate mechanisms of interaction and association between vestibular and otologic symptoms and TMD, but this topic still is controversial. ${ }^{1-11}$

The otologic symptoms related to TMD most cited in the literature are tinnitus, ear pain, ear fullness, hearing loss, and vertigo. $^{5-10}$ In the literature, there are some hypotheses regarding the relationship between otologic symptoms and TMD. ${ }^{3-14}$

Manni ${ }^{8}$ hypothesized that the neurologic signs and symptoms of TMD are correlated based on three theories: (1) the possibility of transmitting mechanical power from the TMJ to the middle ear through the discomaleolar ligament; (2) direct irritation of the mandibular condyle auriculotemporal nerve; (3) hypertonicity of the muscles and the tensor tympani velum, based on common trigeminal innervation of these muscles and masticatory muscles in the jaw. In addition, the poor positioning of the mandibular condyle could cause earache, tinnitus, and vertigo. Another hypothesis explains the occurrence of hyperactivity in the masticatory muscles, which can lead to contraction of the tensor tympani muscle and the tympanic membrane or muscular contraction of the
DOI http://dx.doi.org/ 10.1055/s-0033-1358583. ISSN 1809-9777.
Copyright ( $\odot 2014$ by Thieme Publicações License terms Ltda, Rio de Janeiro, Brazil

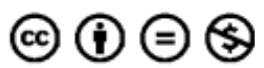


soft palate. This scenario can cause eustachian tube dysfunction leading to ear fullness, imbalance, and hearing loss., ${ }^{3,15}$

Vertigo is a kind of roundabout dizziness, a loss of body balance, observed in many diseases. This condition mainly affects the elderly, and etiologic factors should be investigated to increase the efficiency of treatment. ${ }^{4,7,10}$ Thus, this study aimed to investigate the association between vertigo and TMD in elderly patients.

\section{Materials and Methods}

The study sample consisted of 199 physically independent elderly (mean age: $69.23 \pm 5.70$ years) subjects of both sexes (127 women and 73 men), from a population of 43,610 elderly subjects enrolled in 38 Basic Health Units in the urban area of Londrina. Individuals were randomly selected, taking into account gender and the five regions of the county, as follows: $15 \%$ of the central region, $27 \%$ in the northern region, $23 \%$ in the southern region, $19 \%$ of eastern region and $16 \%$ in the western region. This study is part of EELO Project, developed by the Universidade Norte do Paraná - UNOPAR, of the ethics committee number 00135/12.

The EELO is a multidisciplinary project aimed at integrating a wide variety of topics and health assessments, including economic and psychosocial problems, that enable a comprehensive understanding of the aging process. The data were only collected after the volunteers were informed the objectives of the study and signed the informed consent for any clinical procedure.

Only elderly subjects with natural teeth or prostheses with a functional occlusion were included. Individuals who were toothless and not duly rehabilitated by prostheses were excluded from the study. In addition, patients should have participated in the anamnesis of the audiological evaluation. Only experienced examiners performed all reviews of this research.

The diagnostic evaluation of vertigo consisted for audiological anamnesis based on the Katz protocol used in routine audiology care. $^{16}$

The evaluation of the presence of painful symptoms in the TMJ started with an explanation to the patients on the difference between pressure and discomfort, to obtain reliable answers. This test was performed with bilateral palpation, with the index fingers placed 10 to $20 \mathrm{~mm}$ ahead of the external auditory canal. The lateral aspect of the TMJ was palpated with the patient's mouth closed, and the posterior aspect was palpated with the patient's mouth opened. These regions were pressed continuously and delicately, with a force of $\sim 450$ to $900 \mathrm{~g}$, according to Austin and Pertes. ${ }^{17}$ For muscular palpation, patients received the same orientations regarding the difference between pain and discomfort. The palpation of the masticatory muscles involved the anterior, medial, and posterior temporal and origin, body, and insertion of superficial and deep masseter, which were bilaterally palpated, with a constant pressure of $1,500 \mathrm{~g} .^{18}$ The presence of pain was checked through the eyelid reflex and/or by questioning patients. Cervical muscles (posterior digastric muscle, sternocleidomastoid, and superior trapezius) were palpated by clipping one's fingers like pincers on both sides.

The presence of joint noises based on right and left TMJ inspection was also evaluated. This evaluation was performed by placing the pointer fingers lightly upon the region corresponding to the lateral pole of the condyle, facing the external acoustic meatus, while the patient performed mandibular movements of opening and closing.

Statistical analysis was performed by chi-square tests and odds ratios to determine possible correlations between dizziness and TMD. In the univariate analyses, $p<0.01$ was considered $p<0.001$ highly significant; and $p<0.05$ was used for the inclusion in the final model for the chi-square test and the relative risk value, with $95 \%$ confidence.

\section{Results}

This study showed that there is a significant association between TMD and vertigo. Moreover, the studied elderly people with TMD showed $17.61 \%$ more chance of presenting vertigo than those without TMD (-Table 1). However, there was no significant association between TMD and vertigo when the genders were observed separately ( - Table 2 and - Table 3).

By multiple logistic regression, using the factor "vertigo" as intercept and TMD and gender as independent variables, it was observed that the TMD is a predictor for vertigo but not gender. The result of this regression can be seen in - Table 4 .

Table 1 Complete distribution of TDM in relation to vertigo complaint

\begin{tabular}{|l|l|l|l|l|l|}
\hline \multirow{2}{*}{ TMD } & \multicolumn{4}{|c|}{ Vertigo complaint } \\
\cline { 2 - 7 } & \multicolumn{2}{|c|}{ Yes } & \multicolumn{3}{c|}{ No } \\
\cline { 2 - 7 } & $n$ & $\%$ & 87 & 4 & 43.72 \\
\hline Yes & 54 & 27.14 & 46 & 23.11 & 141 \\
\hline No & 12 & 6.03 & 133 & 66.84 & 199 \\
\hline Total & 66 & 33.17 & & & \\
\hline
\end{tabular}

Abbreviation: Absolute risk reduction, ARR; TMD, temporomandibular disorder.

Note: Odds ratio $=2.3793 ; 95 \%$ confidence interval $1.1577-4.8900 ; x^{2}$ correlation $=5.748(p=0.0256)$. Number needed to cause one adverse event in time $=7 ;$ ARR $=17.61 \%$. 
Table 2 Complete distribution of female patients with TMD and vertigo

\begin{tabular}{|l|l|l|l|l|l|}
\hline \multirow{2}{*}{ TMD } & \multicolumn{4}{|c|}{ Vertigo complaint } & \multirow{2}{*}{ Total } \\
\cline { 2 - 5 } & \multicolumn{4}{|c|}{ Yes } & \multicolumn{2}{c}{ No } & \\
\cline { 2 - 5 } & $n$ & $\%$ & 53 & 42.06 & \\
\hline Yes & 45 & 35.71 & 21 & 16.67 & 126 \\
\hline No & 7 & 5.56 & 74 & 58.73 & \\
\hline Total & 52 & 41.27 & 53 & \\
\hline
\end{tabular}

Abbreviation: Absolute risk reduction, ARR; TMD, temporomandibular disorder.

Note: Odds ratio $=2.5472 ; 95 \%$ confidence interval 0.9918-6.5415; $x^{2}$ correlation $=3.932(p=0.0775)$. Number needed to cause one adverse event in time $=5$; Absolute risk reduction, $A R R=20.92 \%$.

Table 3 Complete distribution of male patients with TMD and vertigo

\begin{tabular}{|c|c|c|c|c|c|}
\hline \multirow[t]{3}{*}{ TMD } & \multicolumn{4}{|c|}{ Vertigo complaint } & \multirow[t]{3}{*}{ Total } \\
\hline & \multicolumn{2}{|c|}{ Yes } & \multicolumn{2}{|c|}{ No } & \\
\hline & $n$ & $\%$ & $n$ & $\%$ & \\
\hline Yes & 9 & 12.33 & 34 & 46.57 & 43 \\
\hline No & 5 & 6.85 & 25 & 34.25 & 30 \\
\hline Total & 14 & 19.18 & 59 & 80.82 & 73 \\
\hline
\end{tabular}

Abbreviation: Absolute risk reduction, ARR; TMD, temporomandibular disorder.

Note: Odds ratio $=1.3235 ; 95 \%$ confidence interval $0.3950-4.4342 ; x^{2}$ correlation $=0.207(p=0.8783)$. Number needed to cause one adverse event in time $=24$; Absolute risk reduction, $A R R=4.26 \%$.

\section{Discussion}

Pathology of the TMJ affects an important part of the population, though it is not viewed as a public health problem. Between 3 and $7 \%$ of the population seeks treatment for pain and dysfunction of the temporomandibular joint (TMJ) or related structures. The literature reports great variability in the prevalence of the clinical symptoms (6 to 93\%) and signs (0 to 93\%), probably as a result of the different clinical criteria used. Age is a risk factor, though with some particularities. In elderly patients, there is an increased prevalence of clinical and radiologic signs, though also a lesser prevalence of symptoms and of treatment demands than in younger adults. Approximately $7 \%$ of the population between 12 and 18 years of age is diagnosed with mandibular pain/dysfunction. ${ }^{19}$

The association of vertigo with TMD has been debated for many years. The observation that patients with TMD have otologic symptoms is confounded because vertigo is a com- mon symptom in the normal population. The mechanism of the association of TMD and otologic symptoms is unknown. ${ }^{5}$

From literature studies, it appears that several distinct mechanisms and comorbidities may be present in the pathophysiology of otologic symptoms, and more specifically, especially of vertigo in relation to TMD, causing its interaction. ${ }^{18,20-27}$

According to D'Antonio et al, ${ }^{20}$ symptoms commonly associated with TMD are headache, tinnitus, ear pain, TMJ noise perception and balance disorders, and problems of malocclusion and painful palpation of temporomandibular structures. In some movements, the mandibular condyles exert pressure on the auriculotemporal nerve near the TMJ capsule, working as a trigger to the painful process along the temporal region.

Williamson ${ }^{21}$ hypothesized that vertigo can result from painful stimuli caused by harmless peridiscal TMJ tissue, which produces arterial constriction in the temporal region and decreases the blood supply to the inner ear vestibular

Table 4 Multiple logistic regression between vertigo, TMD, and gender

\begin{tabular}{|l|l|l|l|}
\hline Multiple logistic regression \\
\hline Intercept: Vertigo & Odds ratio & $195 \% \mathrm{Cl}$ & $p$ value \\
\hline & 2.3950 & $1.16-4.93$ & 0.0178 \\
\hline TMD & 1.3954 & $0.74-2.63$ & 0.3024 \\
\hline Gender
\end{tabular}

Abbreviations: $\mathrm{Cl}$, confidence interval; TMD, temporomandibular disorder. 
region. In the current study, there was an association between TMD and TMJ palpation, masticatory muscles, and cervical muscles.

TMDs are a form of musculoskeletal pain of the TMJ and/ or masticatory muscles of nonspecific etiology. Therefore, the relationship must be found between embryonic and anatomic-topographic similarities of the TMJ and the ear and secondary otologic symptoms that can be closely connected to TMJ disorder. Nonspecific otologic symptoms are not primary diagnostic symptoms of TMD but may cause diagnostic confusion due to patients' inability to correctly locate the origin of pain. The most common otologic symptoms that can be related to TMDs are otalgia, tinnitus, and vertigo. $^{24}$

Middle ear muscles have a common embryologic and functional origin with masticatory and facial muscles. Symptoms referred to the ear may originate from the stomatognathic area. When a primary otologic cause is discarded in the diagnostic workup for tinnitus, vertigo, hypoacusis, hyperacusis, ear pain, or sensation of occluded ear, TMD may be the cause of these symptoms. Among patients with this dysfunction, the prevalence of ear pain, tinnitus, and dizziness varies between 33 and $76 \%{ }^{25}$

To determine the prevalence of aural symptoms in patients with orofacial pain and a potential association between TMD and aural health, while controlling for covariates known to be associated with TMD or auditory dysfunction, a retrospective study was performed with charts of 776 patients. Of the 344 subjects who had TMD, 59.9\% complained of aural symptoms (tinnitus, vertigo, and hearing loss complaints) versus $29.2 \%$ of the 432 patients without TMD. Of the subjects with otalgia, tinnitus, vertigo, or perceived hearing loss, 67, 64.1, 65.2, and $62.2 \%$ had TMD, respectively. Subjects with aural symptoms were significantly more likely to be female, to consider themselves in poor health, to smoke, or to have TMD, orofacial pain, headaches (temporal, occipital, or frontal), neck and shoulder pain, altered vision and sensation, sleep disturbances, loss of appetite, memory loss, or low energy. Clinical findings indicated that pathognomonic signs of TMD were associated with an increased risk of aural complaints in this patient population. A significantly greater negative impact on normal life functions was found in subjects exhibiting aural symptoms versus those who only had TMD complaints. ${ }^{26}$

The prevalence and rank of order of vertigo and other otologic complaints in 200 TMD patients were investigated and compared with an asymptomatic control group. No subjective otologic complaints were reported by 45 (22.5\%) TMD patients; the remaining 155 (77.5\%) patients had at least one otologic complaint. Vertigo was reported by $50 \%$ of the subjects with myofascial pain and dysfunction, by $32.5 \%$ of the patients with internal derangement, and by $41.6 \%$ of the patients with both myofascial pain and dysfunction and internal derangement. However, the incidence of vertigo (14\%) was found to be lower for the control group. Statistically, the control group had fewer vertigo complaints. Patients in the TMD groups had high incidences of vertigo complaints compared with the control subjects without TMD signs or symptoms. ${ }^{27}$
A study was conducted to determine if vertigo is actually more prevalent in patients with TMD than in age-matched controls. One control group was recruited from patients seeking care for health maintenance and the other from patients seeking routine dental care. We surveyed 1,032 patients: 338 had TMD and 694 served as two age-matched control groups. Vertigo was significantly more prevalent in the TMD group than in either of the control groups. ${ }^{5}$

The results of the present study have shown that $27.14 \%$ of the elderly population with vertigo complaints has TMD. According to all studies cited in this research, there was an association between TMD and TMJ palpation, masticatory muscles, and cervical muscles and between TMD with vertigo. The significant association between TMD and vertigo in the studied population demonstrated the importance of identifying risk factors for vertigo that can be modified through specific interventions.

\section{Conclusion}

This research demonstrated a significant association between TMD and vertigo. However, there was no significant association between TMD and vertigo when the genders were observed separately. This significant association in the studied population demonstrated the importance of identifying risk factors for vertigo that can be modified through specific interventions.

\section{References}

1 Pita MS, Ribeiro AB, Zuim PRJ, Garcia AR. Sintomas auditivos e desordens temporomandibulares. Rev Odontol Aracatuba 2010; 31(1):38-45

2 Mcneill CH. Temporomandibular Disorders, Guidelines for Classification, Assessment and Management. The American Academy of Orofacial Pain. Chicago, IL: Quintessence Publishing; 1993

3 Franco AL, Godoi DA, Castanharo SM, Camparis CM. Interaction between headaches and temporomandibular disorders: a literature review. Rev Odontol UNESP 2008;37(4):401-406

4 Levandowski MA, Bueno VK, Marchiori LLM, Melo JJ. Vertigem no idoso: relato de caso. Rev CEFAC 2008;10(4):588-591

5 Chole RA, Parker WS. Tinnitus and vertigo in patients with temporomandibular disorder. Arch Otolaryngol Head Neck Surg 1992;118(8):817-821

6 Keersmaekers KDDS, De Boever JA, Van Den Berghe L. Otalgia in patients with temporomandibular joint disorders. J Prosthet Dent 1996;75(1):72-76

7 Blakley BW, Goebel J. The meaning of the word "vertigo.". Otolaryngol Head Neck Surg 2001;125(3):147-150

8 Manni A, Brunori P, Giuliani M, Modoni M, Bizzi G. Oto-vestibular symptoms in patients with temporomandibular joint dysfunction: electromyographic study. Minerva Stomatol 1996;45:1-7

9 Felício CM, Faria TG, Silva MAMR, Aquino AMCM, Junqueira CA. Desordem Temporomandibular: relações entre sintomas otológicos e orofaciais. Rev Bras Otorrinolaringol 2004;70(6):786-793

10 Bhattacharyya N, Baugh RF, Orvidas L, et al; American Academy of Otolaryngology-Head and Neck Surgery Foundation. Clinical practice guideline: benign paroxysmal positional vertigo. Otolaryngol Head Neck Surg 2008;139(5, Suppl 4):S47-S81

11 Silveira AM, Feltrin PP, Zanetti RV, Mautoni MC. Prevalência de portadores de DTM em pacientes avaliados no setor de otorrinolaringologia. Rev Bras Otorrinolaringol 2007;73(4):528-532 
12 Parker WS, Chole RA. Tinnitus, vertigo, and temporomandibular disorders. Am J Orthod Dentofacial Orthop 1995;107(2):153-158

13 Maixner W, Fillingim R, Sigurdsson A, Kincaid S, Silva S. Sensitivity of patients with painful temporomandibular disorders to experimentally evoked pain: evidence for altered temporal summation of pain. Pain 1998;76(1):(-2):71-81

14 Machado IM, Pialarissi PR, Minici TD, Rotondi J, Ferreira LP. Relação dos sintomas otológicos nas disfunções temporomandibulares. Int Arch Otorhinolaryngol (Impr.) 2010;149(3):274-279

15 Pascoal MIN, Rapoport A, Chagas JFS, Pascoal MBN, Costa CC, Magna LA. Prevalência dos sintomas otológicos na desordem temperomandibular: estudo de 126 casos. Braz J Otorhinolaryngol 2001;67(5):627-633

16 Katz J. Handbook of Clinical Audiology. São Paulo, Brasil: Manole; 1989

17 Austin DG, Pertes RA. Examination of the dysfunction patients. In: Pertes RA, Gross SG, eds. Clinical Management of Temporomandibular Disorders and Orofacial Pain. Chicago, IL: Quintessence; 1995:123-160

18 Conti PC, Ferreira PM, Pegoraro LF, Conti JV, Salvador MC. A crosssectional study of prevalence and etiology of signs and symptoms of temporomandibular disorders in high school and university students. J Orofac Pain 1996;10(3):254-262

19 Poveda Roda R, Bagán JV, Díaz Fernández JM, Hernández Bazán S, Jiménez Soriano Y. Review of temporomandibular joint pathology. Part I: classification, epidemiology and risk factors. Med Oral Patol Oral Cir Bucal 2007;12(4):E292-E298
20 D'Antonio W, Ikno CMY, Castro SM, Balbani APS, Jurado JRP, Bento RF. Distúrbio temporomandibular como causa de otalgia: um estudo clínico. Braz J Otorhinolaryngol 2000;66(1):46-50

21 Williamson EH. The interrelationship of internal derangement of the derangement of the temporomandibular joint, headache, vertigo, and tinnitus: a survey of 25 patients. J Craniomandibular Pract 1990;1:301-306

22 Marchiori LLM, Melo JJ, Possette FLF, Correa AL. Comparação da frequência de queixa de vertigem no idoso com e sem hipertensão arterial. Int Arch Otorhinolaryngol 2010;14(4):456-460

23 Lopes AR, Moreira MD, Trelha CS, Marchiori LLM. Association between complaints of dizziness and hypertension in non-institutionalized elders. Int Arch Otorhinolaryngol 2013;17(2): 157-162

24 Badel T, Savić-Pavicin I, Zadravec D, Marotti M, Krolo I, Grbesa D. Temporomandibular joint development and functional disorders related to clinical otologic symptomatology. Acta Clin Croat 2011; 50(1):51-60

25 Ramírez LM, Ballesteros LE, Sandoval GP. [Otological symptoms among patients with temporomandibular joint disorders]. Rev Med Chil 2007;135(12):1582-1590

26 Lam DK, Lawrence HP, Tenenbaum HC. Aural symptoms in temporomandibular disorder patients attending a craniofacial pain unit. J Orofac Pain 2001;15(2):146-157

27 Tuz HH, Onder EM, Kisnisci RS. Prevalence of otologic complaints in patients with temporomandibular disorder. Am J Orthod Dentofacial Orthop 2003;123(6):620-623 